\title{
0 \\ LAS INFECCIONES DE TRANSMISIÓN SEXUAL: UN PROBLEMA DE SALUD PÚBLICA QUE COLOMBIA DEBE ENFRENTAR
}

\section{ste número de la Revista Colombiana de Obstetricia \\ y Ginecología presenta un reporte de políticas públicas que resume la Estrategia Global de} la Organización Mundial de la Salud (OMS) contra las infecciones de transmisión sexual (ITS) para los años 2016-2021, en cumplimiento de la Agenda 2030 para el Desarrollo Sostenible que acordaron los países pertenecientes a la Organización de las Naciones Unidas (ONU), con el objetivo de lograr las metas para poner fin a la pobreza, proteger el planeta y garantizar la prosperidad para todos (1). El documento se enfoca también en los pasos que deberá dar Colombia para poder cumplir con las metas de la estrategia.

La estrategia, que sigue la aproximación de la OMS a los problemas de salud pública, enfoca la atención en tres infecciones de transmisión sexual: la infección gonocócica, la causada por el virus del papiloma humano y la sífilis, las cuales conllevan serias consecuencias para la salud y la calidad de vida de la población, en el caso colombiano las personas más vulnerables.

El documento hace una serie de recomendaciones a los países para que los gobiernos nacionales definan políticas que permitan orientar acciones sostenibles que, en el tiempo, faciliten la construcción de capacidades institucionales, interinstitucionales y de gobernanza que garanticen la aplicación de las intervenciones que han demostrado ser seguras, efectivas y económicamente viables para el manejo de estas infecciones, con el fin de lograr su impacto en la mayor cantidad de personas vulnerables dentro de un escenario de respeto de los derechos humanos, igualdad de género y equidad en salud (2). Las acciones que incluye la estrategia están enfocadas en: a) el fortalecimiento de la vigilancia, seguimiento y evaluación del progreso del programa; b) la prevención de las ITS; c) el diagnóstico precoz; d) el adecuado manejo de la paciente y su(s) pareja(s), y e) los enfoques para llegar a las poblaciones más vulnerables.

Queremos en este editorial describir la situación de las políticas hacia las ITS en Colombia, por lo que es necesario revisar brevemente cuál ha sido el manejo que se le ha dado en el país a este problema desde los años setenta, y finalizar con algunas propuestas sobre el papel que deben asumir algunos de los actores del sector salud y de otros sectores para poder ser exitosos en la aplicación de esta estrategia en Colombia.

Los primeros registros documentados de las ITS parten del año 1975, con la creación del Sistema Nacional de Salud (SNS). En esa época, el Ministerio de Salud era el encargado de recibir la notificación de las enfermedades transmisibles y no transmisibles (3). El Ministerio planificaba, dirigía, coordinaba, controlaba y ejecutaba las políticas y acciones de salud pública en el país. A nivel regional, esta función estaba a cargo de los Servicios Seccionales de Salud. Hubo grandes éxitos bajo ese modelo, como fue el programa ampliado de inmunizaciones (PAI), pero también hubo fracasos, como el programa de erradicación de la malaria (4). Se tienen informes de notificación de sífilis, tricomoniasis, infección gonocócica y herpes genital desde 1975, sin embargo, no es claro cómo se realizaba el reporte; al parecer, este se hacía con base en el diagnóstico sindromático ya que se informaba 
acerca de casos ulcerativos y de síndrome de secreción uretral. Estos registros llegan hasta el año 2000 (5). En parte de ese periodo se ofrecía en los hospitales públicos la consulta de control de enfermedades venéreas, a la cual asistían las trabajadoras sexuales; allí se buscaba detectar las ITS, y se les daba tratamiento en caso de diagnosticar alguna infección.

Hubo dos situaciones que modificaron la vigilancia y la política estatal en cuanto a las ITS: primero, la aparición del síndrome de inmunodeficiencia adquirida (SIDA) en Estados Unidos y su identificación como infección transmitida sexualmente en 1981 (6), y la posterior identificación del virus de inmunodeficiencia humana (VIH) como causa de este síndrome (7). Los primeros casos se describen en Colombia en 1983 (8), su alta diseminación y mortalidad llevó a que los recursos en el país se centraran en la vigilancia y el tratamiento de esta infección, quedando las otras infecciones de transmisión sexual olvidadas (9). Por otra parte, con la promulgación de la Ley 100 de 1993, se cambió el Sistema Nacional de Salud por un Sistema de Seguridad Social en Salud; a partir de esto, el Ministerio delegó las acciones de promoción y prevención en las aseguradoras, a las que se adscribieron los usuarios ya fueran del régimen contributivo de los trabajadores o aquellas subsidiadas por el Estado. El Ministerio pasó de desempeñar un papel protagónico a un papel normativo en el cual las acciones de salud pública colectiva son ejecutadas por las entidades territoriales bajo lineamientos del Ministerio de Salud, y las acciones individuales por las aseguradoras. La vigilancia y el control se hacen por parte de la Superintendencia de Salud. De esta manera desaparecieron los programas directamente coordinados por el Ministerio, tales como los de vacunación, control de la malaria e infecciones de transmisión sexual (10). Vale la pena anotar que ante la caída de la cobertura de vacunación el Ministerio de Salud debió asumir de manera directa el programa de vacunación como única alternativa para asegurar la calidad del mismo (11).

Según el informe quincenal epidemiológico nacional, todas las infecciones de transmisión sexual habían declinado de manera lineal hasta el año 2000 (5). Es muy posible que este descenso fuera debido más a la ausencia de la notificación, que a una disminución de los casos. En el año 2004 se traslada el sistema de vigilancia al Instituto Nacional de Salud y se reglamenta el Sistema Nacional de Vigilancia en Salud Pública (SIVIGILA) (3). Al revisar los boletines epidemiológicos del SIVIGILA se observa para el año 2006 que la única ITS reportada era la sífilis congénita (12). Para el año 2014 el Boletín Epidemiológico incluye la vigilancia de las siguientes ITS: hepatitis B y C, congénita, y el VIH-SIDA. Para el 2015 se incluye la sífilis gestacional. Es decir, en el momento actual no se está llevando a cabo la vigilancia de los casos de cepas resistentes de $N$. gonorrhoeae, del virus del papiloma humano, como tampoco de C. trachomatis o del virus herpes simple.

En cuanto a la prevención de las ITS, se están llevando a cabo acciones de prevención primaria para el VPH por medio de la inclusión en el plan de beneficios de la vacuna para este virus (13). Sin embargo, la cobertura de vacunación ha caído de manera importante (14) a raíz del miedo de la población a los posibles eventos adversos (15), y el desconocimiento de la población acerca de la importancia de esta intervención. La prevención secundaria en las ITS está orientada al diagnóstico precoz y el tratamiento de la sífilis gestacional y de las mujeres embarazadas con VIH, que hacen parte de la estrategia de eliminación de la transmisión materna infantil (EETMI), de sífilis y VIH, con la cual está comprometida Colombia desde 2011 (16). Como parte de la detección precoz del cáncer cérvico-uterino, la guía colombiana incluye la tamización de los VPH de alto riesgo para cáncer (17). Además, se publicaron las Guías nacionales para manejo sindrómico de las ITS, que ya incluían el uso de pruebas rápidas en el sitio de atención y la unidosis del tratamiento para incrementar la adherencia (18).

No se están haciendo actividades de prevención secundaria en la tamización en población general, por riesgo o por oportunidad para la $N$. gonorrhoeae ni $C$. trachomatis, como tampoco se está haciendo la detección precoz y el tratamiento de la sífilis en poblaciones 
vulnerables como los hombres que tienen sexo con hombres, las trabajadoras sexuales y los habitantes de la calle. El no control de estos focos de infección y reinfección hará muy difícil que se pueda llegar a la meta de eliminación de la sífilis congénita.

Se requiere que el Ministerio de Salud asuma directamente una política de eliminación de las ITS, tal como lo hizo con el programa ampliado de inmunizaciones, ya que no se ha logrado que las aseguradoras (administradoras de planes de beneficios - APB) ejerzan efectivamente las acciones individuales de salud pública en ITS. Como ejemplo de esta situación se tienen las dificultades encontradas en la Evaluación nacional y subnacional de la estrategia de EETMI de sífilis y VIH en los diferentes entes territoriales, para que las empresas administradoras de planes de beneficios ejerzan las acciones individuales que les corresponden en cuanto a: actividades de inducción de la demanda del control prenatal en poblaciones vulnerables, reducción de las barreras de acceso tales como la fragmentación de los servicios o problemas en la contratación que garanticen la disponibilidad de pruebas rápidas en los centros de atención, y el tratamiento del compañero de la paciente con sífilis gestacional (19).

Por otra parte, se requiere disponer de los recursos que den sostenibilidad a un programa de eliminación de las ITS, por ejemplo, con fondos directos de las regalías, o realizar acciones de vigilancia y control para que las APB cumplan con sus obligaciones. Por otra parte, se requiere el esfuerzo de la academia para que, por ejemplo, con fondos del programa de ciencia y tecnología, hacer investigaciones que nos permitan tener información acerca de ITS que no hacen parte de la estrategia, como por ejemplo, la prevalencia de la $C$. trachomatis, $H$. ducreyi o herpes virus en grupos poblacionales; la resistencia del treponema a los macrólidos, o el pronóstico de la enfermedad pélvica inflamatoria en nuestras mujeres. Asimismo, se requiere que las sociedades científicas interesadas en este campo, en especial la Federación Colombiana de Obstétrica y Ginecología, haga control social para que los entes encargados de la salud pública en el país asuman en la realidad los compromisos adquiridos y planifiquen las acciones que reduzcan la inequidad en salud dada por la carga de la enfermedad de las ITS en la población más joven, la más pobre, las etnias, las trabajadoras sexuales y los grupos diversos, las poblaciones más vulnerables a la carga de la enfermedad de las ITS. Además, se requiere de la participación del sector educativo, del sector de las comunicaciones y las tecnologías, y la participación social para poder alcanzar las metas propuestas en la estrategia de eliminación de las ITS.

\section{Hernando Gaitán-Duarte, MD, MSc.}

Editor

\section{REFERENCIAS}

1. Naciones Unidas. Objetivos de Desarrollo Sostenible [visitado 2017 Sep 25]. Disponible en: http://www. un.org/es/comun/docs/?symbol=A/69/L.85

2. World Health Organization. Global Health Sector Strategy on Sexually Transmitted Infections 2016-2021 [visitado 2017 Sep 25]. Disponible en: http://www.who. int/reproductivehealth/publications/rtis/ghss-stis/en/.

3. Instituto Nacional de Salud. Colombia - Sistema Nacional de Vigilancia en Salud Pública (SIVIGILA) 2014- 2016. Antecedentes de la operación estadística [visitado 2017 Sep 25]. Disponible en: https:// formularios.dane.gov.co/Anda_4_1/index.php/ catalog/441/study-description.

4. García M, Eslava JC, Vega-Romero R. La OPS y el Estado colombiano: cien años de historia 19022002 [visitado 2017 Sep 25]. Disponible en: http://www.paho.org/col/index.php?option $=\mathrm{com}_{-}$ docman\&view $=$ download\&category_slug $=$ publicaciones-ops-oms-colombia\&alias $=61$-la-ops-y-el-estado-colombiano-cien-anos-de-historia\&Itemid $=688$.

5. Acosta J, Prieto F, Rodríguez D, Rueda C. Situación de las enfermedades de transmisión sexual, Colombia, 1976-2000. Biomédica. 2002;22 (1):77-88.

6. Centers for Disease Control and Prevention (CDC). Pneumocystis pneumonia-Los Angeles. MMWR. 1981;30:250-2. 
7. Barré-Sinoussi F, Chermann JC, Rey F, Nugeyre MT, Chamaret S, Gruest J, et al. Isolation of a T-lymphotropic retrovirus from a patient at risk for acquired immune deficiency syndrome (AIDS). Science. 1983;220(4599):868-71.

8. Ministerio de Salud y Protección Social - Fondo de Población de las Naciones Unidas (UNFPA). Panorama del VIH/SIDA en Colombia, 1983-2010. Un análisis de situación [visitado 2017 Sep 25]. Disponible en: http:// minsalud.gov.co/salud/Documents/observatorio_vih/ documentos/monitoreo_evaluacion/1_vigilancia_ salud_publica/b_estudios_comportamiento/ PANORAMAVIHCOL_WEB.pdf.

9. Ministerio de Salud. Decreto número 1543 de 1997.

10. Taful LA. El sistema de salud de Colombia. Cuarto foro del proceso de Diseño del Plan de Desarrollo de la Universidad del Valle [visitado 2017 Sep 25]. Disponible en: http://uvsalud.univalle.edu.co/pdf/ plan_desarrollo/documento_previo_4to_foro.pdf

11.Pesquisa Javeriana. Inequidad en las coberturas de vacunación: la mortalidad infantil evitable [visitado 2017 Sep 25]. Disponible en: http://www.javeriana. edu.co/pesquisa/inequidad-en-las-coberturas-devacunacion-la-mortalidad-infantil-evitable/.

12. Instituto Nacional de Salud. Boletín Epidemiológico. 2006;1 (52) [visitado 2017 Sep 25]. Disponible en http://www.ins.gov.co/boletin-epidemiologico/ Boletn\%20Epidemiolgico/2006_VCSP_Boletin_52.pdf.

13. Ministerio de salud y Protección Social. Lineamientos técnicos y operativos para la vacunación contra el virus del papiloma humano (VPH) [visitado 2017 Sep 25]. Disponible en: https://www.minsalud.gov.co/salud/ Documents/Lineamientos\%20VPH.pdf.
14. El Tiempo. Piden incentivar la vacunación contra el virus del papiloma humano. 10 de abril 2017 [visitado 2017 Sep 25]. Disponible en: http://www.eltiempo. com/vida/salud/vacunacion-contra-el-virus-delpapiloma-humano-en-colombia-77018 .

15. Informe Quincenal Epidemiológico Nacional. Brote de evento de etiología desconocida en el municipio de El Carmen de Bolívar, Bolívar, 2014 [visitado 2017 Sep 25]. Disponible en: http://www.ins.gov.co:81/iqen/IQUEN/ IQEN\%20vol\%2020\%202015\%20num\%203_4.pdf

16. Ministerio de la Protección Social. Plan estratégico para la eliminación de la transmisión materno infantil del VIH y la sífilis congénita. Colombia 2011-2015. Bogotá D.C.; febrero 2011.

17. Ministerio de Salud y Protección Social - Colombia. Guía de práctica clínica (GPC) para la detección y manejo de lesiones precancerosas de cuello uterino; 2014 [visitado 2017 Sep 25]. Disponible en: http://gpc. minsalud.gov.co/gpc_sites/Repositorio/Otros_conv/ GPC_Cuello_Uterino/LPC\%20_Guia_completa_ julio_2016.pdf

18. Ministerio de Salud y Protección Social - Colombia. Guía de Práctica Clínica (GPC) para el abordaje sindrómico del diagnóstico y tratamiento de los pacientes con infecciones de transmisión sexual y otras infecciones del tracto genital [visitado 2017 Sep 25]. Disponible en http://gpc.minsalud.gov.co/gpc_sites/Repositorio/ Conv_500/GPC_its/GPC_its_completa.aspx

19. Ministerio de Salud y Protección Social. Organización Panamericana de la Salud (OPS). Evaluación Nacional y Subnacional del avance de la estrategia nacional para la Eliminación de la Transmisión Materno Infantil del VIH y de la sífilis congénita. Bogotá; 2016. 